\title{
Review \\ Clinical Update on Patient-Controlled Analgesia for Acute Postoperative Pain
}

\author{
Cyrus Motamed
}

check for

updates

Citation: Motamed, C. Clinical

Update on Patient-Controlled

Analgesia for Acute Postoperative

Pain. Pharmacy 2022, 10, 22. https://

doi.org/10.3390/pharmacy10010022

Academic Editor: Joseph V. Pergolizzi

Received: 12 November 2021

Accepted: 25 January 2022

Published: 27 January 2022

Publisher's Note: MDPI stays neutral with regard to jurisdictional claims in published maps and institutional affiliations.

Copyright: (C) 2022 by the author. Licensee MDPI, Basel, Switzerland. This article is an open access article distributed under the terms and conditions of the Creative Commons Attribution (CC BY) license (https:// creativecommons.org/licenses/by/ $4.0 /)$.
Department of anesthesia, Gustave Roussy Cancer Campus, 94080 Villejuif, France; cyrus.motamed@gustaveroussy.fr

\begin{abstract}
Patient-controlled analgesia (PCA) is an effective method for controlling acute pain, including postoperative pain in adults and in children from five years of age, pain resulting from labor, trauma, or other medical situations, or chronic and malignant pain. The treatment consists of a mini-computer-controlled infusion pump permitting the administration of on-demand, continuous, or combined doses of analgesic (mainly opioid) variations in response to therapy, which allows pain to be significantly controlled. Intravenous (IV)-PCA minimizes individual pharmacodynamics and pharmacokinetic differences and is widely accepted as a reference method for mild or severe postoperative pain. IV-PCA is the most studied route of PCA; other delivery methods have been extensively reported in the literature. In addition, IV-PCA usually voids the gap between pain sensation and analgesic administration, permitting better recovery and fewer side effects. The most commonly observed complications are nausea and vomiting, pruritus, respiratory depression, sedation, confusion and urinary retention. However, human factors such as pharmacy preparation and device programming can also be involved in the occurrence of these complications, while device failure is much less of an issue.
\end{abstract}

Keywords: acute pain; postoperative pain; intravenous morphine; patient-controlled analgesia; PCA

\section{Introduction}

Patient-controlled analgesia (PCA) has been used since the early 1970s to relieve multiple categories of pain, including acute, such as postoperative or labor pain, or chronic, such as palliative care or cancer pain [1,2]. The goal of PCA is to efficiently deliver pain relief at a patient's preferred dose and schedule by allowing them to administer a predetermined bolus dose of medication on-demand at the press of a button [3]. Boluses can be administered alone or coupled with a continuous background infusion of opioids using a dedicated pump.

According to the revised international association for the study of pain definition [4] the new definition of pain is the following: An unpleasant sensory and emotional experience associated with, or resembling that associated with, actual or potential tissue damage. Acute pain is a type of pain that lasts less than 3 months and is generally related to soft tissue injury or damage, such as cuts. It gradually resolves as the injured tissues heal. One of the most common types of acute pain is postoperative pain, which arises in the aftermath of surgery.

Although significant improvement has been made in the anticipation and management of postoperative pain in recent decades, a non-negligible percentage of patients might still have moderate to severe postoperative pain [5].

Patient-controlled analgesia (PCA) preceded by initial intravenous titration is an effective strategy for postoperative analgesia, as it may rapidly provide an adequate analgesic dose upon arrival at the postoperative care unit (PACU).

While intravenous and epidural administration remain the most commonly used modes of PCA, several alternative modes are also available in the clinical setting. These 
alternative routes of administration include oral, transdermal, inhaled and intranasal, each with its own potential benefits or risks [3].

\section{Methods}

This paper update is a narrative review of only opioid IV-PCA (essentially morphine) for clinicians involved in the management of acute postoperative pain. The search strategy used three electronic databases: PubMed (MEDLINE/Index Medicus), the Cochrane (Controlled Trials Register) and Google Scholar, which were searched for pertinent studies and reviews published between January 2010 and December 2021; animal studies were excluded. Search items included postoperative pain, PCA, patient-controlled analgesia, opioids, parenteral opioids, opioid side effects and morphine. When new updated information was not available older studies were referenced in some areas.

\section{Results/Discussion}

Surgery can result in moderate or severe pain, which can initiate complications in the postoperative period after the procedure. Although anticipation of postoperative pain and its management has been positive for decades, a significant proportion of patients still have high pain scores with non-optimal pain relief [3-5].

\subsection{Predictors of Postoperative Pain}

Predictors of postoperative pain and analgesic consumption have been assessed in several studies [6-12]. The severity of postoperative pain is multifactorial and complex [13]. These factors include preexisting pain, anxiety, age, type of surgery, need for information, genetic factors and history of smoking. Type of surgery, age and psychological distress are the main predictive factors for postoperative analgesic consumption [6,7]. In addition, a practical approach is also reported to be useful by assessing pain score on venous cannulation before surgery [14].

\subsection{Indications and Benefits of PCA}

PCA indications are large, since many surgeries yield high pain scores. Several risk factors for high postoperative pain scores have been established [6,7]. Nearly all types of surgery that yield high postoperative pain can be treated with IV-PCA in the acute phase; examples of such surgeries include spine and other complex orthopedic surgeries, such as knee and hip [15], open abdominal [16] and non-ambulatory laparoscopic surgery [17]; and thoracic [18], major cervicofacial and reconstruction surgeries [19], including breast surgeries [20]. In addition to initial severe postoperative pain, some surgeries can also yield chronic postoperative pain such as cardiac [21], knee [22] shoulder [23] and hip pain [24]. Therefore, special attention should be paid to these surgeries to propose the most efficient technique for patients, which might not be IV-PCA in some circumstances (Table 1).

It is generally recognized that the benefits of PCA are adaptation to individual patients' needs by giving patients control over their own pain, relatively fast onset of action, predictable drug delivery and side effects, and high scores of satisfaction, despite suboptimal postoperative pain relief in some specific surgeries $[18,25]$.

Table 1. Options for components of multimodal postoperative pain therapy for commonly performed surgeries.

\begin{tabular}{cccc}
\hline & $\begin{array}{c}\text { PCA IV and/or Other } \\
\text { Systemic Therapies * }\end{array}$ & $\begin{array}{c}\text { Side Specific Infiltration or } \\
\text { Block with or without } \\
\text { Regional Catheters ** }\end{array}$ & $\begin{array}{c}\text { Neuraxial Anesthetic } \\
\text { Techniques } * * *\end{array}$ \\
\hline Thoracotomy/thoracoscopy & ++ & Paravertebral block ++ & +++ \\
\hline Laparotomy & ++ & $\begin{array}{c}\text { Infiltration catheters } \\
\text { TAP block } \\
+\end{array}$ & +++ \\
\hline
\end{tabular}


Table 1. Cont.

\begin{tabular}{|c|c|c|c|}
\hline & $\begin{array}{l}\text { PCA IV and/or Other } \\
\text { Systemic Therapies* }\end{array}$ & $\begin{array}{l}\text { Side Specific Infiltration or } \\
\text { Block with or without } \\
\text { Regional Catheters } * *\end{array}$ & $\begin{array}{c}\text { Neuraxial Anesthetic } \\
\text { Techniques } * * *\end{array}$ \\
\hline Laparoscopy & +++ & Infiltration ++ & + \\
\hline Hip & +++ & ++ & ++ \\
\hline Knee & ++ & +++ & ++ \\
\hline Shoulder/upper arm & ++ & +++ & \\
\hline Spinal fusion & +++ & & ++ \\
\hline Cesarean section & ++ & TAP block ++ & +++ \\
\hline Breast surgery & ++ & Paravertebral block +++ & \\
\hline $\mathrm{CABG}$ & +++ & & \\
\hline Cervicofacial surgery & +++ & +++ When indicated & \\
\hline & \multicolumn{3}{|c|}{$\begin{array}{l}{ }^{*} \text { Opioids/non-steroidal anti-inflammatory drugs/Gabapentin or pregabalin/IV ketamine/; }{ }^{* *} \text { Block such as } \\
\text { femoral, fibular and paravertebral; TAP = transverse abdominal plain block using local anesthetics; }{ }^{* *} \text { Epidural } \\
\text { with local anesthetics (with or without intrathecal opioid). Most of these surgeries are also reported to yield } \\
\text { chronic post-surgical pain }[9,10,21,26-32] .+: \text { moderate indication, }++: \text { acceptable indication, }+++: \text { good indication. }\end{array}$} \\
\hline
\end{tabular}

\subsection{Interindividual Variability}

Multiple studies involving morphine for postoperative analgesia display a wide range of inter- or intra-individual variability in morphine requirements but also in plasma morphine concentrations [33-36]. By adapting to patients' needs, PCA is highly compliant with interindividual needs.

\subsection{PCA Concept}

The effectiveness of PCA is mostly related to the old concept of "minimal effective analgesic concentration" (MEAC), defined as the smallest plasma concentration of morphine at which the pain is relieved [37]. To achieve this concentration, a preliminary titration is necessary, while further adjustments with automatic bolus administered by the patient permit navigation in what is generally described as an analgesic corridor. Trespassing the upper limit of this corridor results in opioid side effects, while exiting the lower limit of this corridor results in the inefficiency of pain relief [38] (Figure 1).

To reach this target, a controlled and progressive increase in the plasma level of opioids is necessary, which is achieved by titration. Titration means that the drug is administered as a bolus of small doses [38]. Titration of morphine in the operating room during wound closure or PACU is generally the first step of IV opioid management. Morphine by titration in PACU requires previous pain assessment by caretakers, generally a numeric verbal scale less than 3-4 on an 11-grade scale ( 0 no pain, 10 worst 'maximal'). Titration provides relatively rapid analgesia and the ability to adapt the dose to interindividual variability requirements until the establishment of a clinically acceptable analgesia pattern is obtained; however, on some occasions, another opioid can be used before adequate pain relief is achieved [39].

Morphine, a hydrophilic agent and hydromorphone, remains the most commonly used drug for postoperative analgesic titration compared to lipophilic opioids such as fentanyl, sufentanil, alfentanil, or remifentanil [39], as these opioids have a faster onset but also a shorter duration of action.

The maximum concentration after a bolus injection is around six minutes, explaining the delay between further titration injection or the "lock out" period necessary while PCA is used $[36,40]$. During this lockout time, the PCA pump does not permit further delivery, permitting each bolus to reach the peak effect before the next bolus reducing the risk of overdose. 


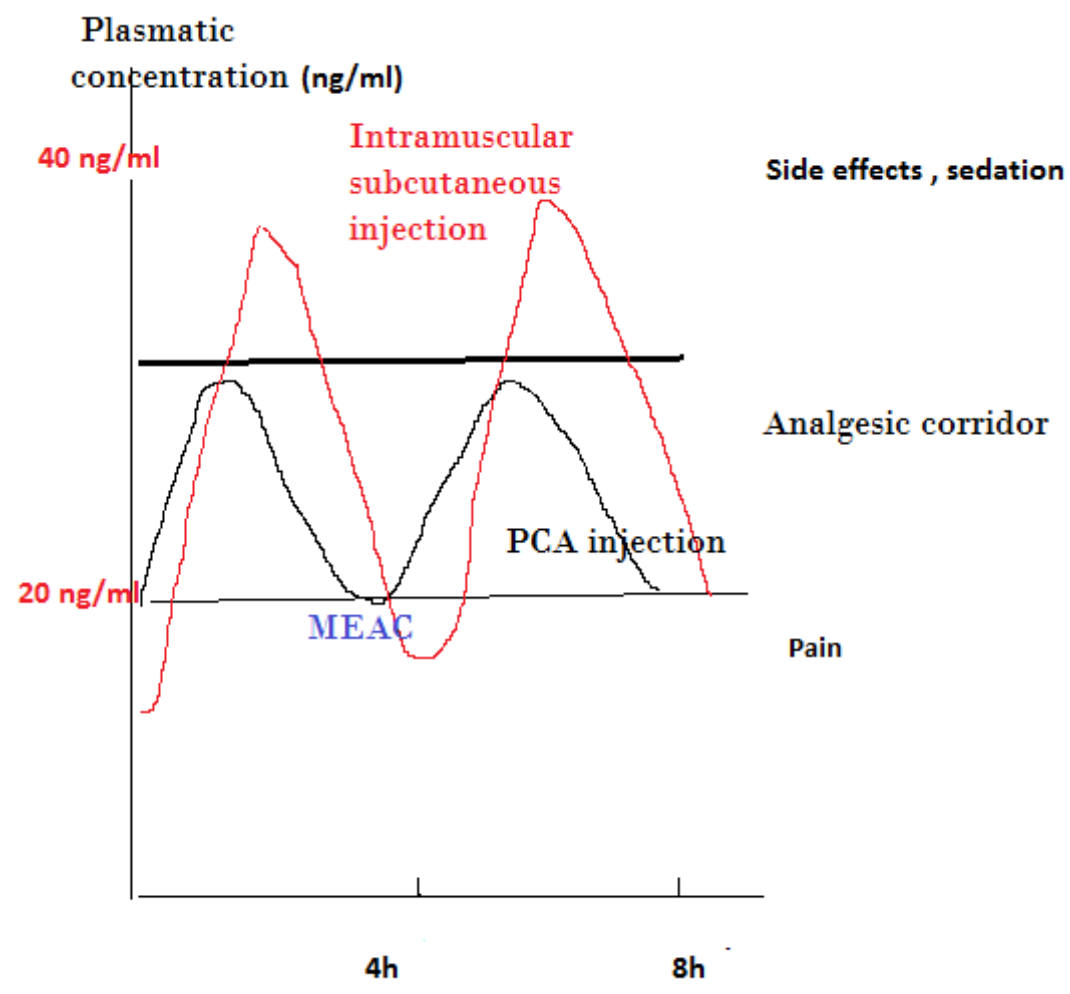

Figure 1. Presentation of analgesic corridor concept: subcutaneous or intramuscular injection vs. PCA IV injection of lower dose of opioid. MEAC, minimum effective analgesic concentration.

IV morphine titration allows the dose to be adapted to the patients' needs and can provide reliable immediate relief of postoperative pain after a wide range of surgical interventions in both young and elderly patients [38]. Titration needs individual adaptation, as the subsequent injection should consider also what has already been administered. Factors affecting early morphine requirements include ethnicity, emergency, major surgery, long-lasting surgery and high pain score upon arrival to PACU [41].

It should be emphasized that morphine titration to alleviate acute postoperative pain might not always be effective or possible due to the early appearance of side effects or other complicating factors, such as tachyphylaxis; therefore, it is appropriate to define an alert dose for titration to use alternative methods to alleviate pain [38].

\subsection{Side Effects of IV-PCA}

Most side effects of opioids administered via PCA are related to opioids, such as nausea and vomiting, sedation, apnea, hypoxemia, hypoventilation, pruritus and postoperative delirium (POD).

The ventilatory depressant effects of morphine are the most serious side effects. Although they can be patient-related, they are mostly related to a default in preparation, prescription, or administration, as well as a device failure.

A recent comparison of the side effects of different opioids given in an equianalgesic dose revealed that no significant or clinically relevant difference should be expected in terms of nausea, vomiting and pruritus when comparing different types of opioids [42].

Considering POD, a recent study did not find a difference in its incidence between morphine IV-PCA and fentanyl patient-controlled epidural analgesia (PCEA). After a propensity score matching patient characteristics, it was concluded that POD occurs regardless of the route and dose of opioid administration [43].

Naloxone is reported to decrease the overall incidence of opioid side effects. A pooled analysis study examining IV naloxone (either as a continuous infusion or IV-PCA) revealed a decrease in pruritus and nausea with no increase in pain scores. Overall, the use of 
IV naloxone is not associated with any significant changes in opioid consumption nor with the risk of sedation or emesis [3,44]. In other more recent study, low and ultra-low doses such as $0.25 \mu \mathrm{g} / \mathrm{kg}$ are also reported to reduce pain intensity due to morphine consumption, pruritus and nausea [45,46]; finally, Pieters [47] found that a high dose naloxone of $0.5 \mathrm{mg} / \mathrm{kg} / \mathrm{h}$ was not more efficient in reducing opioid side effects, despite partially reversing the analgesic effect of opioid by yielding an increase in demand on postoperative day 2 .

While IV-PCA can be used in most types of surgery, it may not provide the best quality of analgesia, especially in dynamic conditions. For example, in open abdominal surgery, epidural analgesia has been considered the gold standard for perioperative analgesia and provides significantly better pain relief both at rest and in dynamic situations [25]. However, after the implementation of enhanced recovery after surgery (ERAS) protocols more than a decade ago and a shift from open to laparoscopic surgery, the advantage of epidural anesthesia has diminished, requiring the use of other opioids and methods, such as intravenous ketamine, peripheral nerve blocks, continuous wound infiltration, intrathecal morphine, intravenous and non-invasive PCA [48].

Although the literature praising PCA-IV for its efficiency in controlling multiple entities of postoperative pain is abundant, according to systematic reviews, the quality of pain relief as determined by assessment of pain intensity scores was only slightly superior to specific non-PCA technique-controlled parenteral opioid (iv, IM, SC) regimens; in two meta-analyses [33,34], PCA is reported to provide superior quality of analgesia with only moderate to low evidence. In addition, despite involving a slightly higher dose of opioid consumption, no increase in opioid-induced side effects is disclosed. Modern surgeries support the use of multimodal regimens in many situations.

As effective and safe alternatives to traditional PCA and with the added benefits of being non-invasive, easy to use and making early patient mobilization possible, newer PCA systems may complement multimodal pain management or replace certain regimens in hospitalized patients with acute postoperative pain [49] (Table 2).

Table 2. Bolus dose and lockout period with different opioids medications.

\begin{tabular}{ccc}
\hline Analgesic & Bolus Dose & Lockout Period (Minutes) \\
\hline Morphine & $1 \mathrm{mg}$ & $5-10$ \\
\hline Fentanyl & $10 \mu \mathrm{g}$ & $5-10$ \\
\hline Hydromorphone & $0.25 \mathrm{mg}$ & $5-10$ \\
\hline Remifentanil & $0.5 \mu \mathrm{g} / \mathrm{kg}$ & 2 \\
\hline Sufentanil & $5 \mu \mathrm{g}$ & $5-10$ \\
\hline
\end{tabular}

Explaining the PCA pump system to patients is generally performed before surgery at the anesthetic consultation; however, re-instruction after surgery is reported to be effective for optimizing PCA to increase the quality of analgesia. In this way, patients use this technique more efficiently, especially when multiple variables, including dynamic pain, are integrated [50].

In terms of patient's satisfaction, PCA is again reported to have an edge over non-PCA methods, which does not necessarily mean that the quality of analgesia is superior to the alternative technique [51].

\subsection{Comparison of Different PCA Medications}

Although several opioids have been studied for use in IV-PCA, according to systematic reviews, there is not enough significant clinical evidence to consider the relevant superiority of other opioids on postoperative analgesia compared to morphine IV [33,34] (Tables 2 and 3). 
Table 3. Comparison of different opioids when used in a PCA mode [52-54].

\begin{tabular}{|c|c|c|}
\hline & Efficiency & Side Effects \\
\hline Oxycodone & As potent as morphine & May have fewer severe side effects \\
\hline Hydromorphone & & Higher incidence of CNS side effects, excitation at higher dose \\
\hline Fentanyl & $\begin{array}{l}\text { High potency }+ \text {, may require more need } \\
\text { for basal infusion rate }\end{array}$ & $\begin{array}{l}\text { Lesser incidence of respiratory depression in comparison to } \\
\text { morphine, but more programming errors }\end{array}$ \\
\hline Sufentanil & $\begin{array}{l}\text { High potency }++ \text {, high therapeutic index, } \\
\text { more predictable profile, more need for } \\
\text { basal infusion }\end{array}$ & Lower incidence of PONV in comparison to fentanyl \\
\hline Tramadol & Ten times less potent than morphine & More PONV in some type of surgeries (e.g., spinal fusion) \\
\hline Remifentanil & $\begin{array}{l}\text { Very short duration, studies mainly } \\
\text { in labor }\end{array}$ & $\begin{array}{c}\text { Higher respiratory depression, less satisfaction in comparison } \\
\text { to epidural analgesia }\end{array}$ \\
\hline
\end{tabular}

CNS, central nervous system; PONV, postoperative nausea and vomiting. +: moderate indication, ++: acceptable indication.

\subsection{Adding Ketamine to PCA Morphine}

Two recent papers $[55,56]$ investigated the combination of ketamine and opioid IVPCA, confirming the conclusion of a previous meta-analysis whereby the addition of ketamine to opioid PCA slightly improves postoperative pain intensity and PONV and decreases cumulative morphine consumption. Nevertheless, Matsota et al. found tramadol to be superior compared to ketamine as an adjuvant to morphine IV-PCA [56].

\subsection{Human-Related Issues and Side Effects}

A major human issue associated with adverse effects is non-anticipated/authorized administration of IV bolus doses of an analgesic by either family, friends, or hospital staff, known as PCA by proxy [57]. In a database error analysis, 460 out of 6069 PCA errors resulted in patient harm or death. Twelve out of the 460 errors were attributed to PCA by proxy, with one patient death resulting from nurse-activated PCA [58]. Errors produced by proxy administration programming might also contribute to death from PCA [58-60]. In addition, cassette preparation error might yield variation in morphine infusion preparation, leading to inaccuracy of infusion delivery to patients [61].

Multiple and/or successive individual or collective errors can combine to result in a serious adverse event. Both equipment design and human factors play a critical role at multiple levels in generating serious adverse events [62]. On the other hand, PCA can sparsely hide symptoms related to other painful pathologies, such as myocardial infarction, thromboembolism, or acute limb ischemia, which implies vigilance and careful evaluation of opioid consumption in the postoperative period [63].

\subsection{PCA in Children}

Morphine titration is appropriate pain management in pediatric patients because of the limitation in dosage and decreasing the incidence of adverse events. Nevertheless, interindividual variation is also present in this population.

Opioid infusions in children are useful, but adequate dosing and titration require careful supervision. Nevertheless, morphine titration in pediatrics has limitations, as pain scores are not always obtainable in the PACU and the validity of self-reported pain intensity scores may be unreliable in children with developmental and neurological disabilities, thereafter affecting the analgesic protocol and necessitating close monitoring [47,48].

Morphine PCA is used for children above 4-6 years of age experiencing painful surgery, such as scoliosis and pectus excavatum repair [64,65]. In addition, for those children unable to handle or understand the concept, PCA by proxy (mainly administered by nurses) remains a safe and efficient method of pain administration for this population, except for children suffering from developmental and neurological disabilities $[64,66,67]$. 


\subsection{PCA for Elderly and Frail Patients}

Elderly patients represent a large and rapidly increasing proportion of surgical patients. Management of postoperative pain should focus on minimizing adverse effects.

In normal elderly patients, titration should not be much different; however, for patients older than 90 years and frail patients, a protocol using boluses of $1-2 \mathrm{mg}$ with a greater time interval and a limitation of the total dose is recommended [68].

A retrospective study involving over 10,575 patients comparing older and younger patients using IV fentanyl PCA concluded that, when IV-PCA was used for postoperative pain control, a higher percentage of younger patients required rescue analgesics, while elderly patients required more rescue antiemetics. The addition of ketorolac or ramosetron to the PCA of young and elderly patients can be effective in preventing rescue analgesic or antiemetic use [69]. On the other hand, the cost effectiveness of PCA for elderlies has also been questioned in a small group of orthopedic patients detecting under-use of the device, thus questioning the adequate pre- or postoperative explanations to this category of patients [70].

\subsection{PCA in Obese Patients}

Obese patients with obstructive sleep apnea (OSA) are at an increased risk of upper airway obstruction and require close monitoring. Intermittent IV injections of morphine boluses can be used in these patients. Obesity prolongs the elimination half-life of lipophilic drugs such as fentanyl and sufentanil; however, morphine may be used cautiously in patients with sleep apnea syndrome (OSA) without non-invasive positive pressure [18]. Indeed, the lipophilic properties of morphine may result in different tissue concentrations, in addition to a significant decrease in clearance of its glucoronide metabolites [71], in obese patients, placing them at higher risk of respiratory depression.

PCA, without a background infusion, is a safe and effective method of analgesic delivery. However, if patients are known to have OSA, more intensive monitoring is recommended [72].

\subsection{PCA in Chronic Pain Patients}

Opioid-tolerant patients require additional adjustments when using IV-PCA as the main source of analgesia. Opioid-tolerant patients have significantly higher opioid requirements compared to opioid-naïve patients in the intra- and postoperative period [73]; therefore, adequate postoperative analgesic anticipation is highly recommended [5]. Initial postoperative titration might be difficult using a rapid titration strategy. Using remifentanil in combination with traditional titration effort might help to decrease the time to achieve clinically acceptable levels of pain relief in a better condition [39], while, postoperatively, these patients may often require additional IV continuous infusion doses.

\subsection{Recent Modalities of PCA Administration}

New modalities of PCA administration are currently under investigation. Lee et al. described a variable feedback infusion rate plus demand in comparison to the constant baseline infusion model plus demand in spinal fusion surgery, whereby the variable model used significantly less analgesic and had significantly less demand than the constant base model; however, there was no difference in side effects [74]. Recently, Jung et al. also described a similar model in laparoscopic cholecystectomy patients whereby the cumulative morphine requirements were significantly less in the optimized background infusion mode, with no difference in the rate of antiemetic use. More studies of different type of surgery are needed before generalizing these modes of administration [75].

\subsection{Other Factors Influencing Quality of Pain Management}

Besides adequate titration, non-pharmacological factors could play a part in optimum pain relief, such as preoperative teaching, adequately addressing patients' concerns about 
pain assessment and information about pumps. Adequate knowledge of these factors should help in better clinical care and outcome.

\subsection{Limitation of This Study}

Limitations of this study include a bias selection, as the quality of the studies was not classified, and their interpretation, which might have been biased by the own experience of the author.

\section{Conclusions}

Despite the lack of new evidence, IV-PCA administration of opioids, especially morphine, has only a light superiority for quality of analgesia compared to non-PCA opioidbased analgesic regimens. Nevertheless, morphine IV-PCA, as a component of multimodal analgesia for acute postoperative pain, remains a well-accepted/adopted technique by patients and health care providers, resulting in a high level of satisfaction, while the incidence of side effects is equivalent to non-PCA opioid-based techniques. This modality of analgesia will still be valid and useful for the coming years, pending careful selection of patients with appropriate indications.

Funding: This work received no external funding and the APC was provided by the author itself.

Institutional Review Board Statement: Not applicable.

Informed Consent Statement: Not applicable.

Data Availability Statement: Not applicable.

Conflicts of Interest: The author declare no conflict of interest.

\section{References}

1. Evans, J.M.; Rosen, M.; MacCarthy, J.; Hogg, M.I. Apparatus for patient-controlled administration of intravenous narcotics during labour. Lancet 1976, 1, 17-18. [CrossRef]

2. Evans, J.M.; Rosen, M.; McCarthy, J.; Hogg, M.J. Letter: Patient-controlled intravenous narcotic administration during labour. Lancet 1976, 1, 906-907. [CrossRef]

3. Viscusi, E.R. Patient-controlled drug delivery for acute postoperative pain management: A review of current and emerging technologies. Reg. Anesth. Pain Med. 2008, 33, 146-158. [CrossRef] [PubMed]

4. Raja, S.N.; Carr, D.B.; Cohen, M.; Finnerup, N.B.; Flor, H.; Gibson, S.; Keefe, F..; Mogil, J.S.; Ringkamp, M.; Sluka, K.A.; et al. The revised International Association for the Study of Pain definition of pain: Concepts, challenges, and compromises. Pain 2020, 161, 1976-1982. [CrossRef] [PubMed]

5. Motamed, C.; Salazar, G.; Bourgain, J.L. Incidence of severe postoperative pain after cancer surgery despite intraoperative anticipation: A case controlled study. Bull. Cancer 2010, 97, E37-E41. [CrossRef] [PubMed]

6. Coppes, O.J.M.; Yong, R.J.; Kaye, A.D.; Urman, R.D. Patient and Surgery-Related Predictors of Acute Postoperative Pain. Curr. Pain Headache Rep. 2020, 24, 12. [CrossRef]

7. Yang, M.M.H.; Hartley, R.L.; Leung, A.A.; Ronksley, P.E.; Jette, N.; Casha, S.; Riva-Cambrin, J. Preoperative predictors of poor acute postoperative pain control: A systematic review and meta-analysis. BMJ Open 2019, 9, e025091. [CrossRef]

8. Borges, N.C.; Pereira, L.V.; de Moura, L.A.; Silva, T.C.; Pedroso, C.F. Predictors for Moderate to Severe Acute Postoperative Pain after Cesarean Section. Pain Res. Manag. 2016, 2016, 5783817. [CrossRef]

9. Charalampidis, A.; Rundberg, L.; Moller, H.; Gerdhem, P. Predictors of persistent postoperative pain after surgery for idiopathic scoliosis. J. Child Orthop. 2021, 15, 458-463. [CrossRef]

10. Costelloe, C.; Burns, S.; Yong, R.J.; Kaye, A.D.; Urman, R.D. An Analysis of Predictors of Persistent Postoperative Pain in Spine Surgery. Curr. Pain Headache Rep. 2020, 24, 11. [CrossRef]

11. Joo, J.; Moon, H.K.; Moon, Y.E. Identification of predictors for acute postoperative pain after gynecological laparoscopy (STROBEcompliant article). Medicine 2019, 98, e17621. [CrossRef] [PubMed]

12. Luedi, M.M.; Schober, P.; Hammoud, B.; Andereggen, L.; Hoenemann, C.; Doll, D. Preoperative Pressure Pain Threshold Is Associated With Postoperative Pain in Short-Stay Anorectal Surgery: A Prospective Observational Study. Anesth. Analg. 2021, 132, 656-662. [CrossRef] [PubMed]

13. Nelson, E.R.; Gan, T.J.; Urman, R.D. Predicting Postoperative Pain: A Complex Interplay of Multiple Factors. Anesth. Analg. 2021, 132, 652-655. [CrossRef] [PubMed]

14. Persson, A.K.M.; Akeson, J. Prediction of Acute Postoperative Pain from Assessment of Pain Associated With Venous Cannulation. Pain Pract. 2019, 19, 158-167. [CrossRef] 
15. Choi, S.W.; Cho, H.K.; Park, S.; Yoo, J.H.; Lee, J.C.; Baek, M.J.; Jang, H.D.; Cha, J.S.; Shin, B.J. Multimodal Analgesia (MMA) Versus Patient-Controlled Analgesia (PCA) for One or Two-Level Posterior Lumbar Fusion Surgery. J. Clin. Med. 2020, 9 , 1087. [CrossRef]

16. Akter, N.; Ratnayake, B.; Joh, D.B.; Chan, S.J.; Bonner, E.; Pandanaboyana, S. Postoperative Pain Relief after Pancreatic Resection: Systematic Review and Meta-Analysis of Analgesic Modalities. World J. Surg. 2021, 45, 3165-3173. [CrossRef]

17. Niu, L.; Chen, L.; Luo, Y.; Huang, W.; Li, Y. Oxycodone versus morphine for analgesia after laparoscopic endometriosis resection. BMC Anesthesiol. 2021, 21, 194. [CrossRef]

18. Sun, K.; Liu, D.; Chen, J.; Yu, S.; Bai, Y.; Chen, C.; Yao, Y.; Yu, L.; Yan, M. Moderate-severe postoperative pain in patients undergoing video-assisted thoracoscopic surgery: A retrospective study. Sci. Rep. 2020, 10, 795. [CrossRef]

19. Qin, M.; Chen, K.; Liu, T.; Shen, X. Dexmedetomidine in combination with sufentanil for postoperative analgesia after partial laryngectomy. BMC Anesthesiol. 2017, 17, 66. [CrossRef]

20. Vanni, G.; Caiazza, G.; Materazzo, M.; Storti, G.; Pellicciaro, M.; Buonomo, C.; Natoli, S.; Fabbi, E.; Dauri, M. Erector Spinae Plane Block Versus Serratus Plane Block in Breast Conserving Surgery: Alpha Randomized Controlled Trial. Anticancer Res. 2021, 41, 5667-5676. [CrossRef]

21. Bonnesen, K.; Nikolajsen, L.; Boggild, H.; Hostrup Nielsen, P.; Jacobsen, C.J.; Viemose Nielsen, D. Chronic post-operative opioid use after open cardiac surgery: A Danish population-based cohort study. Acta Anaesthesiol. Scand. 2021, 65, 47-57. [CrossRef] [PubMed]

22. Wilson, L.; Fiasconaro, M.; Liu, J.; Poeran, J.; Poultsides, L.; Memtsoudis, S.G. Risk of chronic opioid use after simultaneous versus staged bilateral knee arthroplasty. Reg. Anesth. Pain Med. 2021, 46, 405-409. [CrossRef] [PubMed]

23. Hamilton, G.M.; Tierney, S.; Ramlogan, R.; McCartney, C.J.L.; Bromley, L.A.; McIsaac, D.I. Persistent Postoperative Opioid Prescription Fulfillment and Peripheral Nerve Blocks for Ambulatory Shoulder Surgery: A Retrospective Cohort Study. Anesthesiology 2021, 135, 829-841. [CrossRef] [PubMed]

24. Anoushiravani, A.A.; Kim, K.Y.; Roof, M.; Chen, K.; O'Connor, C.M.; Vigdorchik, J.; Schwarzkopf, R. Risk factors associated with persistent chronic opioid use following THA. Eur. J. Orthop. Surg. Traumatol. 2020, 30, 681-688. [CrossRef]

25. Motamed, C.; Spencer, A.; Farhat, F.; Bourgain, J.L.; Lasser, P.; Jayr, C. Postoperative hypoxaemia: Continuous extradural infusion of bupivacaine and morphine vs patient-controlled analgesia with intravenous morphine. Br. J. Anaesth. 1998, 80, 742-747. [CrossRef]

26. Benedetti, M.G.; De Santis, L.; Mariani, G.; Donati, D.; Bardelli, R.; Perrone, M.; Brunelli, S. Chronic pain in lower limb amputees: Is there a correlation with the use of perioperative epidural or perineural analgesia? NeuroRehabilitation 2021, 49, 129-138 [CrossRef]

27. Chappell, A.G.; Yuksel, S.; Sasson, D.C.; Wescott, A.B.; Connor, L.M.; Ellis, M.F. Post-Mastectomy Pain Syndrome: An Up-to-Date Review of Treatment Outcomes. JPRAS Open 2021, 30, 97-109. [CrossRef]

28. Clephas, P.R.D.; Hoeks, S.E.; Trivella, M.; Guay, C.S.; Singh, P.M.; Klimek, M.; Heesen, M. Prognostic factors for chronic postsurgical pain after lung or pleural surgery: A protocol for a systematic review and meta-analysis. BMJ Open 2021, 11, e051554 [CrossRef]

29. Liu, C.W.; Page, M.G.; Weinrib, A.; Wong, D.; Huang, A.; McRae, K.; Fiorellino, J.; Tamir, D.; Kahn, M.; Katznelson, R.; et al Predictors of one year chronic post-surgical pain trajectories following thoracic surgery. J. Anesth. 2021, 35, 505-514. [CrossRef]

30. Kim, K.H.; Lee, C.K.; Kim, S.H.; Kim, Y.; Kim, J.E.; Shin, Y.K.; Seok, J.; Cho, H.M. Prevalence of chronic post-thoracotomy pain in patients with traumatic multiple rib fractures in South Korea: A cross-sectional study. Sci. Rep. 2021, 11, 2615. [CrossRef]

31. Samara, E.; Stamatiou, K.; Economou, S.; Tzimas, P. Post Laparoscopy Neuropathic Pain Treated by Capsaicin $8 \%$ Dermal Patch. J. Pain Palliat. Care Pharmacother 2021, 35, 123-125. [CrossRef]

32. Zinboonyahgoon, N.; Patton, M.E.; Chen, Y.K.; Edwards, R.R.; Schreiber, K.L. Persistent Post-Mastectomy Pain: The Impact of Regional Anesthesia Among Patients with High vs Low Baseline Catastrophizing. Pain Med. 2021, 22, 1767-1775. [CrossRef] [PubMed]

33. Hudcova, J.; McNicol, E.; Quah, C.; Lau, J.; Carr, D.B. Patient controlled opioid analgesia versus conventional opioid analgesia for postoperative pain. Cochrane Database Syst. Rev. 2006, 4, CD003348. [CrossRef]

34. McNicol, E.D.; Ferguson, M.C.; Hudcova, J. Patient controlled opioid analgesia versus non-patient controlled opioid analgesia for postoperative pain. Cochrane Database Syst. Rev. 2015, 6, CD003348. [CrossRef]

35. Tyler, D.C.; Pomietto, M.; Womack, W. Variation in opioid use during PCA in adolescents. Paediatr. Anaesth. 1996, 6, 33-38. [CrossRef] [PubMed]

36. Upton, R.N.; Semple, T.J.; Macintyre, P.E. Pharmacokinetic optimisation of opioid treatment in acute pain therapy. Clin. Pharmacokinet. 1997, 33, 225-244. [CrossRef] [PubMed]

37. Austin, K.L.; Stapleton, J.V.; Mather, L.E. Relationship between blood meperidine concentrations and analgesic response: A preliminary report. Anesthesiology 1980, 53, 460-466. [CrossRef]

38. Aubrun, F.; Mazoit, J.X.; Riou, B. Postoperative intravenous morphine titration. Br. J. Anaesth. 2012, 108, 193-201. [CrossRef]

39. Motamed, C.; Weil, G.; Deschamps, F.; Billard, V. Remifentanil target-controlled infusion: A safe rescue protocol for unexpected severe postoperative pain. J. Opioid. Manag. 2014, 10, 284-288. [CrossRef]

40. Semple, T.J.; Upton, R.N.; Macintyre, P.E.; Runciman, W.B.; Mather, L.E. Morphine blood concentrations in elderly postoperative patients following administration via an indwelling subcutaneous cannula. Anaesthesia 1997, 52, 318-323. [CrossRef] 
41. Dahmani, S.; Dupont, H.; Mantz, J.; Desmonts, J.M.; Keita, H. Predictive factors of early morphine requirements in the postanaesthesia care unit (PACU). Br. J. Anaesth. 2001, 87, 385-389. [CrossRef] [PubMed]

42. Dinges, H.C.; Otto, S.; Stay, D.K.; Baumlein, S.; Waldmann, S.; Kranke, P.; Wulf, H.F.; Eberhart, L.H. Side Effect Rates of Opioids in Equianalgesic Doses via Intravenous Patient-Controlled Analgesia: A Systematic Review and Network Meta-analysis. Anesth. Analg. 2019, 129, 1153-1162. [CrossRef]

43. Miyoshi, H.; Nakamura, R.; Noda, Y.; Yokomi, H.; Kamiya, S.; Morio, A.; Watanabe, T.; Narasaki, S.; Toyota, Y.; Saeki, N.; et al. Intravenous patient-controlled analgesia does not increase the risk of postoperative delirium compared to patient-controlled epidural analgesia: A propensity score-matched retrospective cohort study. Ann. Palliat. Med. 2021. [CrossRef] [PubMed]

44. Murphy, J.D.; Gelfand, H.J.; Bicket, M.C.; Ouanes, J.P.; Kumar, K.K.; Isaac, G.R.; Wu, C.L. Analgesic efficacy of intravenous naloxone for the treatment of postoperative pruritus: A meta-analysis. J. Opioid. Manag. 2011, 7, 321-327. [CrossRef] [PubMed]

45. Barrons, R.W.; Woods, J.A. Low-Dose Naloxone for Prophylaxis of Postoperative Nausea and Vomiting: A Systematic Review and Meta-analysis. Pharmacotherapy 2017, 37, 546-554. [CrossRef] [PubMed]

46. Firouzian, A.; Gholipour Baradari, A.; Alipour, A.; Emami Zeydi, A.; Zamani Kiasari, A.; Emadi, S.A.; Kheradmand, B.; Hadadi K. Ultra-low-dose Naloxone as an Adjuvant to Patient Controlled Analgesia (PCA) With Morphine for Postoperative Pain Relief Following Lumber Discectomy: A Double-blind, Randomized, Placebo-controlled Trial. J. Neurosurg. Anesthesiol. 2018, 30, 26-31. [CrossRef]

47. Pieters, B.J.; Anderson, J.T.; Price, N.; Anson, L.M.; Schwend, R.M. Low-Dose Versus High-Dose Postoperative Naloxone Infusion Combined With Patient-Controlled Analgesia for Adolescent Idiopathic Scoliosis Surgery: A Randomized Controlled Trial. Spine Deform. 2018, 6, 430-434. [CrossRef]

48. Wagemans, M.F.; Scholten, W.K.; Hollmann, M.W.; Kuipers, A.H. Epidural anesthesia is no longer the standard of care in abdominal surgery with ERAS. What are the alternatives? Minerva. Anestesiol. 2020, 86, 1079-1088. [CrossRef]

49. Morlion, B.; Schafer, M.; Betteridge, N.; Kalso, E. Non-invasive patient-controlled analgesia in the management of acute postoperative pain in the hospital setting. Curr. Med. Res. Opin. 2018, 34, 1179-1186. [CrossRef] [PubMed]

50. Piccioni, F.; Doronzio, A.; Brambilla, R.; Melis, M.; Langer, M. Integration of pain scores, morphine consumption and demand/delivery ratio to evaluate patient-controlled analgesia: The C-SIA score. Korean J. Anesthesiol. 2017, 70, 311-317. [CrossRef]

51. Engsusophon, P.; Laosuwan, P.; Songthamwat, B.; Wattanachai, P.; Ussawanopkiat, M.; Charuluxananan, S. Factors Influencing Patient Satisfaction on Patient-Controlled Analgesia (PCA) for Postoperative Pain Management. Thai J. Anesthesiol. 2019, 45, 15-19.

52. Kim, K.T.; Kim, C.K.; Kim, Y.C.; Juh, H.S.; Kim, H.J.; Kim, H.S.; Hong, S.J.; Hey, H.W.D. The effectiveness of low-dose and high-dose tranexamic acid in posterior lumbar interbody fusion: A double-blinded, placebo-controlled randomized study. Eur. Spine J. 2017, 26, 2851-2857. [CrossRef]

53. Lu, G.; Yao, W.; Chen, X.; Zhang, S.; Zhou, M. Remifentanil patient-controlled versus epidural analgesia on intrapartum maternal fever: A systematic review and meta-analysis. BMC Pregnancy Childbirth 2020, 20, 151. [CrossRef]

54. Lee, W.; Gao, X.; Tang, J.; Li, A.; Zhu, Y.; Ling, X.; Cang, J.; Fang, F. Postoperative sufentanil intravenous patient-controlled analgesia within the first $24 \mathrm{~h}$ : A retrospective study. Ann. Palliat. Med. 2020, 9, 3932-3937. [CrossRef]

55. Brinck, E.C.V.; Virtanen, T.; Makela, S.; Soini, V.; Hynninen, V.V.; Mulo, J.; Savolainen, U.; Rantakokko, J.; Maisniemi, K.; Liukas, A.; et al. S-ketamine in patient-controlled analgesia reduces opioid consumption in a dose-dependent manner after major lumbar fusion surgery: A randomized, double-blind, placebo-controlled clinical trial. PLoS ONE 2021, 16, e0252626. [CrossRef]

56. Matsota, P.K.; Koukopoulou, I.C.; Kalimeris, K.A.; Kyttari, A.C.; Drachtidi, K.H.; Kostopanagiotou, G.G. Ketamine Versus Tramadol As an Adjunct To PCA Morphine for Postoperative Analgesia After Major Upper Abdominal Surgery: A Prospective, Comparative, Randomized Trial. Rom. J. Anaesth. Intensive Care 2020, 27, 43-51. [CrossRef]

57. van Heijster, S.; Janssen, J.; Sarton, E.; Niesters, M.; Dahan, A. Postoperative opioid overdose due to patient-controlled analgesia by proxy. Ned. Tijdschr. Geneeskd. 2020, 164, D5084.

58. Vicente, K.J.; Kada-Bekhaled, K.; Hillel, G.; Cassano, A.; Orser, B.A. Programming errors contribute to death from patientcontrolled analgesia: Case report and estimate of probability. Can. J. Anaesth. 2003, 50, 328-332. [CrossRef]

59. Flynn, F.; Mohr, L.; Lawlor-Klean, P. Right programming of pumps to prevent errors in the infusion process. Jt. Comm. J. Qual. Saf. 2003, 29, 37-40. [CrossRef]

60. Rashed, A.N.; Tomlin, S.; Aguado, V.; Forbes, B.; Whittlesea, C. Sources and magnitude of error in preparing morphine infusions for nurse-patient controlled analgesia in a UK paediatric hospital. Int. J. Clin. Pharm. 2016, 38, 1069-1074. [CrossRef]

61. Rashed, A.N.; Tomlin, S.; Forbes, B.; Whittlesea, C. Current practice of preparing morphine infusions for nurse/patient-controlled analgesia in a UK paediatric hospital: Healthcare professionals' views and experiences. Eur. J. Hosp. Pharm. 2018, 25, 327-330. [CrossRef]

62. Syed, S.; Paul, J.E.; Hueftlein, M.; Kampf, M.; McLean, R.F. Morphine overdose from error propagation on an acute pain service. Can. J. Anaesth. 2006, 53, 586-590. [CrossRef]

63. Finger, M.J.; McLeod, D.G. Postoperative myocardial infarction after radical cystoprostatectomy masked by patient-controlled analgesia. Urology 1995, 45, 155-157. [CrossRef]

64. Dinter, K.; Bretschneider, H.; Zwingenberger, S.; Disch, A.; Osmers, A.; Vicent, O.; Thielemann, F.; Seifert, J.; Bernstein, P. Accelerate postoperative management after scoliosis surgery in healthy and impaired children: Intravenous opioid therapy versus epidural therapy. Arch. Orthop. Trauma Surg. 2021. [CrossRef] 
65. Dekonenko, C.; Dorman, R.M.; Duran, Y.; Juang, D.; Aguayo, P.; Fraser, J.D.; Oyetunji, T.A.; Snyder, C.L.; Holcomb, G.W., 3rd; Millspaugh, D.L.; et al. Postoperative pain control modalities for pectus excavatum repair: A prospective observational study of cryoablation compared to results of a randomized trial of epidural vs patient-controlled analgesia. J. Pediatr. Surg. 2020, 55, 1444-1447. [CrossRef]

66. Sharp, D.; Jaffrani, A. A PRISMA systematic review on the safety and efficacy of patient-controlled analgesia (PCA) in pediatrics. J. Pediatr. Nurs. 2021, 61, 219-223. [CrossRef]

67. Cravero, J.P.; Agarwal, R.; Berde, C.; Birmingham, P.; Cote, C.J.; Galinkin, J.; Isaac, L.; Kost-Byerly, S.; Krodel, D.; Maxwell, L.; et al . The Society for Pediatric Anesthesia recommendations for the use of opioids in children during the perioperative period. Paediatr. Anaesth. 2019, 29, 547-571. [CrossRef]

68. Aubrun, F.; Marmion, F. The elderly patient and postoperative pain treatment. Best Pract. Res. Clin. Anaesthesiol. 2007, 21, 109-127. [CrossRef]

69. Koh, J.C.; Lee, J.; Kim, S.Y.; Choi, S.; Han, D.W. Postoperative Pain and Intravenous Patient-Controlled Analgesia-Related Adverse Effects in Young and Elderly Patients: A Retrospective Analysis of 10,575 Patients. Medicine 2015, 94, e2008. [CrossRef]

70. Brown, A.; Boshers, B.; Chapman, L.F.; Huckaba, K.; Pangle, M.; Pogue, L.C.; Potts, M.; Ray, E.; Thomason, N.; Poynter, A.; et al. Do Elderly Patients Use Patient-Controlled Analgesia Medication Delivery Systems Correctly? Orthop. Nurs. 2015, 34, 203-208. [CrossRef]

71. de Hoogd, S.; Valitalo, P.A.J.; Dahan, A.; van Kralingen, S.; Coughtrie, M.M.W.; van Dongen, E.P.A.; van Ramshorst, B.; Knibbe, C.A.J. Influence of Morbid Obesity on the Pharmacokinetics of Morphine, Morphine-3-Glucuronide, and Morphine-6-Glucuronide. Clin. Pharmacokinet. 2017, 56, 1577-1587. [CrossRef]

72. Levin, A.; Klein, S.L.; Brolin, R.E.; Pitchford, D.E. Patient-controlled analgesia for morbidly obese patients: An effective modality if used correctly. Anesthesiology 1992, 76, 857-858. [CrossRef]

73. Motamed, C.; Audibert, J.; Albi-Feldzer, A.; Bouroche, G.; Jayr, C. Postoperative pain scores and opioid consumption in opioiddependent patients with cancer after intraoperative remifentanil analgesia: A prospective case-controlled study. J. Opioid. Manag. 2017, 13, 221-228. [CrossRef]

74. Lee, S.H.; Baek, C.W.; Kang, H.; Park, Y.H.; Choi, G.J.; Jung, Y.H.; Woo, Y.C. A comparison of 2 intravenous patient-controlled analgesia modes after spinal fusion surgery: Constant-rate background infusion versus variable-rate feedback infusion, a randomized controlled trial. Medicine 2019, 98, e14753. [CrossRef]

75. Jung, K.T.; So, K.Y.; Kim, S.U.; Kim, S.H. The Optimizing Background Infusion Mode Decreases Intravenous Patient-Controlled Analgesic Volume and Opioid Consumption Compared to Fixed-Rate Background Infusion in Patients Undergoing Laparoscopic Cholecystectomy: A Prospective, Randomized, Controlled, Double-Blind Study. Medicina 2021, 57, 42. [CrossRef] 